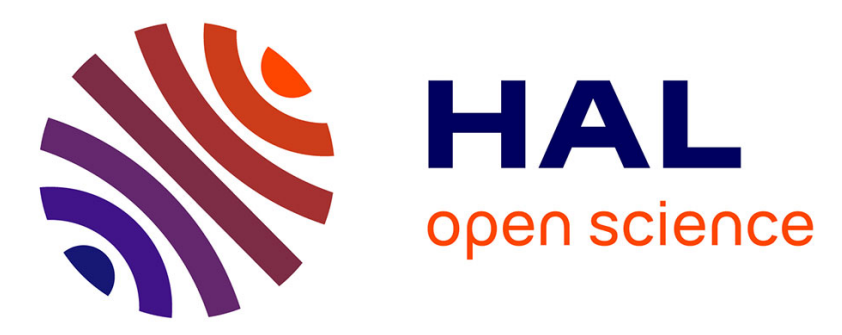

\title{
From Transactions to Relationships: Making Sense of User-Centered Perspectives in Large Technology-Intensive Companies
}

\author{
Petra Björndal, Elina Eriksson, Henrik Artman
}

\section{To cite this version:}

Petra Björndal, Elina Eriksson, Henrik Artman. From Transactions to Relationships: Making Sense of User-Centered Perspectives in Large Technology-Intensive Companies. 4th IFIP 13.6 Working Conference on Human Work Interaction Design (HWID), Jun 2015, London, United Kingdom. pp.114124, 10.1007/978-3-319-27048-7_8. hal-01371793

\section{HAL Id: hal-01371793 \\ https://hal.inria.fr/hal-01371793}

Submitted on 9 Nov 2016

HAL is a multi-disciplinary open access archive for the deposit and dissemination of scientific research documents, whether they are published or not. The documents may come from teaching and research institutions in France or abroad, or from public or private research centers.
L'archive ouverte pluridisciplinaire HAL, est destinée au dépôt et à la diffusion de documents scientifiques de niveau recherche, publiés ou non, émanant des établissements d'enseignement et de recherche français ou étrangers, des laboratoires publics ou privés. 


\title{
From Transactions to Relationships: Making Sense of User-Centered Perspectives in Large Technology- Intensive Companies
}

\author{
Petra Björndal ${ }^{1,2}$, Elina Eriksson ${ }^{2}$, and Henrik Artman ${ }^{2}$ \\ 1 ABB Corporate Research, Västerås, Sweden \\ Petra.bjorndalese.abb.com \\ $2 \mathrm{KTH}$, Royal Institute of Technology, Stockholm, Sweden \\ \{elina, artman\}@kth.se
}

\begin{abstract}
In this paper we analyze interviews from four technology-intensive companies, focused on service and service development. All companies have during the last two decades introduced interaction design units, and the corporations were selected due to their interest in also expanding the service share of their business. This service shift has been a top-down initiative. However in only two companies, the initiatives have led to the establishment of enterprise wide service development processes, and in the other two companies, the service development is more ad hoc. It is argued that even if interaction design has close theoretical relation to service design such combination has so far been limited. We discuss the shift from product to service view of the offerings within these companies, and relate this to user-centered perspectives. We argue there is a window of opportunity within technology-intensive and engineering focused industries to include user-centered design when formalizing service development.
\end{abstract}

Keywords: User-centered design - Service design - Service development · Usability $\cdot$ Technology intensive companies

\section{Introduction}

Today, technology-intensive product manufacturers go through a shift that addresses fundamental parts of their economy, when business models go from transaction based to relationship based. This transition process is called servitization and create organizational, structural as well as process challenges [1]. To some degree, the servitization process seems almost inevitable for the technology intensive product manufacturing companies, and in management literature, powerful arguments are put forward to integrate service into their core offerings along three lines, economic arguments, customer demands and competitiveness (ibid.). Taking a service perspective put a focus on how the processes are deployed and for whom, rather than focusing on the technology in itself. One might say that service has a focus centered on the experience and fluency relative the business customer. This resembles in a sense imperatives of user

adfa, p. 1, 2011.

(C) Springer-Verlag Berlin Heidelberg 2011 
centered design and interaction design where the user and user experience are in focus. Put into comparison, the concurrent drive for service in part mirror how businesses adopted and incorporated the user centered design (UCD) and usability movement. The UCD and usability movement started academically as early as 1940's but it was through the extended use of computers in industry during the 1980's and forward that made companies employ usability experts. Today larger companies often have at least smaller units with UCD and interaction designers. The process of introducing UCD and usability departments in companies has been slow, in most cases bottom-up and customer demanded [2]. This UCD shift has been playing out differently in different domains. The engineering heavy industries, well-grounded in the industrialization, have put much pride in their technology and few engineering companies have until recently been advertising their products as user friendly or with similar connotations. Instead the excellence of their technology has been focused on the product; the technology itself.

While UCD and interaction design brings focus to user needs and task decomposition relative computerization, service offerings put focus on a higher level of experience which include all forms of aspects relative the business that the industries are offering. Neither UCD nor service development ignores or diminish the technological part, but both put more emphasis on aspects which more or less presuppose that the backend of the technology is there and is (excellently) functional. It is interesting to compare such perspective shifts in general but specifically it is interesting to see if and how the two perspective shifts can be combined.

This work explores the view on service and service development among people working in-house in four global industrial companies and is based on interviews and observations. With help of the empirical material we discuss central concepts in UCD and compare it to the ongoing perspective shift in these companies.

\section{Background}

The companies within which we have done interviews, are industrial and technologyintensive. However, the focus of the technology is to solve a particular problem in a certain setting and to center technology around certain contexts implicitly include an understanding of a person that use the technology. Below we will present two different approaches which explicitly focuses on this addressed person.

\subsection{Evolving User-Centered Approaches}

Although human-computer interaction $(\mathrm{HCl})$ is a relatively young research field it has undergone rapid changes and new sub areas have emerged in a fast pace. The perspectives within the field has evolved and is reflected in various user focused practices. HCI has it origin in the disciplines ergonomics and human factors, which are experimental approaches and treats the interaction as an isolated phenomenon. The focus is the machine performance and the unit of analysis is user actions of one person in front 
of a display. Human factors is criticized for isolating actions from the complex context in which they take place [3].

As a result of the increase in number of computers in working life, demands for ease of use emerged as well as for practical, not so costly, methods to develop usable systems. Usability emerged as a topic and in the end of the 1980s the user-centered approach evolved as an emphasis for the designer to focus more on the user and to give users an active role [4]. Usability was defined by an international standard as "The extent to which a product can be used by specified users to achieve specified goals with effectiveness, efficiency and satisfaction in a specified context of use" [5]. Furthermore, the computer supported computer work (CSCW) research community grew out of the need to extend the user concept into involving groups of users as well as a multitude of computers. Further on, the technical evolution of a networked society resulted in new challenges and concerns. Earlier clear boundaries between work and leisure have become vague and the significance of the physical location has been altered. Bødker points to the need in HCI to extend the view of context to also include settings outside the physical workplace and she outlines new interests in culture, emotion and experience growing from the shift from always designing purposeful and rational solutions [8]. Such perspectives on HCI have been coined interaction design which have a more design oriented, in contrast to analytical, view on HCI and UCD.

\subsection{Evolving Marketing Approaches}

Studies of service development started as early as in the 70s marketing research [9], and the evolvement of this subject has mainly been done within the marketing and management disciplines. Service marketing has a history of breaking out of marketing research, i.e. the goods marketing perspective, and has thus reinforced the differences between service and goods to justify the sub discipline.

In the 2000s new arguments was formulated on how to describe and conceptualize service. Vargo and Lusch presented their service dominant logic describing service in a value creation perspective [10]. They are arguing for an interpretation of value as "value in use" contrarily "value in exchange". They defined business processes as service and argue to not distinguish goods and service, instead goods are means for service delivery. A central theme in their arguments is that customers are integrating knowledge and capabilities with the service provider's personnel and artifacts in a cocreation of value. This way of describing value has changed how market research characterizes customers, from passive to active co-creators, and puts an emphasis on the importance of involving customers in the development process [11]. So far, the discussion in market research has been on a conceptual level, with little result on how to put these ideas into practice [12].

\subsection{Where the Strands Meet}

Branching out from the HCI field in the 2000s, service design became a new interdisciplinary movement with a root in design thinking [13]. It was based primarily on two drivers; firstly the growing service sector supported by experience focused and 
knowledge-intensive solutions, and secondly initiatives in user-centered disciplines where people recognized the benefit of combining user-centered practices with service development and innovation. For example, Holmlid discusses how service design can help to open up the earlier sometimes impeding focus on computer mediation and the computer as a tool perspective in HCI [14]. The argument is that this movement can give complementing views to earlier approaches, using multiple channels and a diversity in possible ways to create user value. Wetter-Edman has researched the contribution of design practice and design theory in realizing the service dominant logic ideas [15], [16]. She shows how user-centered methods are complementary for user involvement and co-creation and can open up new perspectives on value. She also shows that the valuable role of the designer as an interpreter and intermediator between customer and company, is lacking in marketing research approaches. The possible connection between user-centered approaches and service development points towards positive future concurrence.

Since the implementation of user-centered methods has been slow and gained relatively little impact in industrial product development, we approached service practitioners within these companies. These service practitioners do not always have an outspoken task to realize their respective organizations demand on an increased share of service. With an underlying interest in seeing where user-centered perspectives can meet service development, we aimed to investigate how these practitioners talk about service, how they perceive their role and how the servitization process has been played out within these companies.

\section{Method}

The material for this paper has been collected from four large international companies selling business to business solutions in different domains, here denoted company A, B, C and D. All four companies are global, with a history in traditional engineering fields, and they all have operations in at least Africa, America, Asia, and Europe and more than 35000 employees each worldwide. At company A, 7 interviews were conducted, labeled 1:A to 7:A. To further broaden the picture, 5 additional interviews were done with representatives from company B, C and D, i.e. 8: B, 9:B, 10:C, 11:C, and 12:D. The sample of interviewees have been chosen in consultation with contact persons with a good knowledge of their companies view on service, and where based on two criteria, 1) perceived long experience of service delivery/development within the company and 2) some kind of responsibility in regard to this. The 12 semistructured interviews took place between April 2013 and June 2013.

All interviewees had some kind of management role; concerning projects, methods and/or personnel. 9 out of 12 worked close to or in relatively close connection to customers. Two worked with technical development enabling service delivery, and one worked on a strategic level. 11 out of 12 had an engineering background, and one had training in service management. One of the persons mentioned knowledge of UCD. The interviews took around one hour each, and 14.5 hours of recorded material were transcribed verbatim. 7 of the interviews were done in Swedish and 5 in English. The 
original Swedish quotes were translated to English by the authors. Moreover, to gather more information, 3 on-site observations were conducted in company A. The observations were focused on delivering value to customers; two cases of remote service and onsite service delivery. Additional material was also collected from respective companies' web site.

The transcribed material was collected in Atlas.ti, a common qualitative data analysis software. Furthermore the data analysis were made primarily by the first author, using techniques from grounded theory, specifically inspired by the constructivist grounded theory approach described by Charmaz [17]. During the initial coding the transcribed material was worked through in detail, followed by a more focused coding phase were some key issues was followed up and further explored. These key issues formed emerging themes that were in an iterative process, revisited and refined, together with the field material and information from the web sites.

\section{$4 \quad$ Results and Analysis}

In this section we will both recount what status service development have in these four companies and contrast service development with user-centered design and usability through some key concepts.

\subsection{Service Status in the Studied Companies}

The companies studied for this paper are all mainly technology-intensive organizations with a prevailing engineering culture and have all a long tradition of developing and selling products, where providing spare parts for the products have been their main service business. In line with this prevailing engineering attitude, the format and the specifications of the products produced becomes noticeably important. This is reflected in the organizational structure where different parts of the organizations are dealing with specific product families. When service packages are created, our interviewees explained that these are often seen as separate components added on to the products. In the same vein, service departments have been added as isolated entities into the existing organization. Budgets, tools, and resources often follow these organizational boundaries, which contribute to silo thinking and complicate collaboration between different departments.

Frequently, you find several pieces of equipment from the same producing company at one customer site, but with limited coordination between the departments delivering these products or service. Our interviewees explain that there is a tension between adding service components onto existing products, and by so reinforce the silos, and the wish to solve the customer's problem regardless whether it is a motor or a robot that stopped the production for the customer. This is similar to what Winter et al. have observed, where the organizational set up created conflicts of interest between departments, and giving cause to breakdowns in communication [2]. Hence, there are budding service initiatives within the studied companies, but their organizational belonging is still under construction. 


\subsection{Top Down Incentives for Service}

Within all the studied companies, the top management have emphasized the importance of increasing the percentages of revenues coming from service which is manifested e.g. in strategies and policies. Hence, these companies are compelling examples of the current servitization process as exemplified by the following quote from company C: "As times goes on, the greater scope service will get, I'm quite sure [...] it is more and more important you have value-added service. There is probably a stated goal [...] we should have a certain proportion of service. We will be more service oriented as a company" [10:C]

However, these top down encouraged initiatives does not necessarily mean there is a widespread knowledge about service and service development within the companies we have studied. Hence there is a frustration among people working with service, they are encouraged, or even prompted to develop service revenue, but they seem to be lacking clear goals on what this would be as in the following quote: "The closest they [the middle management] has come to service may be that they have purchased a TV subscription as a service, they have poor understanding of what service is all about, so now when they get this directive from the top management, "now, work with service', of course, they do not know what to do" [11:C]

Not only is there a lack of knowledge, our interviewees also express a concern that support for those supposed to implement the service initiatives are also largely lacking: "they expect the most and put the least in the service organization" [7:A].

Service in these organizations could be more than something on top of their products, it could include also the knowledge base of what and how the products may provide value in specific contexts. Still as the quotes above indicate this has not yet become a central position of their business - possibly a consequence of a firm grounding in a product focused mindset. The top-management initiatives have not been that thoroughly grounded in the practices of the organization and their employees which may hinder the servitization process.

\subsection{Service Development}

All of the studied companies had standardized and clear product development processes, but only two of the organizations had at the time for the interviews defined the processes for service development. Some of the interviewees from companies with defined service development processes, describes that it is difficult to diffuse the process: "the difficulty that I've seen anyway, is how we roll out the stuff and get this to work practically out there" [10:C]

Worth noting is that despite there being defined processes in two of the companies, most services in all four organizations were actually developed ad-hoc. As a consequence of this, service is developed in different ways in different parts of the organization, and the resulting solutions are often not coordinated. There are initiatives to mitigate this problem and to create company-wide offerings out of these ad hoc solutions, as explained in this quote: "the service is created out there, sold and delivered 
a couple of times before it is washed off a little before it is introduced into the global portfolio" [8:B]

Reports of the ad-hoc development process are mixed, mentioning both positive as well as negative aspects. There is a pride in the solutions that have been made, but at the same time people feel out of control and without any overview, as exemplified in the following quote: "there is a mentality to fix things, an entrepreneurship, and this has created very good stuff, what is worse then is that you might not know what you have done, and what opportunities are available" [1:A]

At this point in time it is difficult to elaborate on the role of a service process in these companies since they are in two cases nonexistent and in the other two cases not widely spread. What can be deduced though is that the interviewees express a wish to have a more structured way of working.

\subsection{Use of the Concept Service}

The word service, is not well-defined and agreed upon in these organizations. Even if the interviewees worked with service in their daily work, they had difficulties explaining the concept. This was common in all companies, the interviewees expressed a confusion about what other people working in the same organization meant by service, as indicated by these two quotes: "it is all context dependent, of course, talking internal [A] how I see it, it [service] is very wide and very unclear" [6:A], "the service concept is so unclear [...] it means that there are lots of people who develop this who does not understand it is service they develop" [12:D]

Also the very different categories of service can complicate the communication, especially since maintenance and spare parts are viewed by many as being equal to service in this context. As of today service in these companies can cover for example; agreements, training, spare parts, software, maintenance, consulting, analyzes and financing. This complicate things as this interviewee explains: "if you talk to people, they will mix all those things together [...] if you talk to some people, they talk about the services needed to get the system going, a bunch of people see services to operate [x], so it is a confusing picture to people" [9:B]

From the interviews, it is clear that the term service must be defined and grounded in the organization, in order for the service development to work satisfactorily.

\subsection{The Customer in Focus}

Traditionally, service in these companies has meant maintenance and spare parts tightly coupled to particular products but the perspective oriented towards more product transcended knowledge has begun to gain some support. The former is firmly based on a technological orientation, where the product has a central role, while the latter case is focusing more on what the customer wants to be done, more or less independent of what products might be used. These two views have different implications as the former will focus on one form of equipment while the latter will focus on how different equipment can be combined and integrated in order to fulfill a certain objective. Our interviewees talk about their offerings in terms of a whole, with a cer- 
tain goal to make the clients work process work smoothly and it is this system that delivers the value for the receiver: "We handle both our own products that can be installed there and our competitors, we handle maintenance of automation products, systems, electrical equipment, mechanical equipment and everything else, so we take total responsibility for the maintenance. For a production site [...] we have a common goal together with the client" [4:A]

This perspective puts the customer in the center, and this is a strength the interviewees point to, the tradition of long term relationships to the customers. Previously this has been due to the long life time, sometimes decades, of the equipment they are selling. However, the use of the term customer by the interviewees can be problematic to interpret as a customer is not necessarily the same person as a user [5]. The ISO definition of a user is "a person who interacts with the product" [6], and a customer "organization or person that receives a product or service" [7]. In the transcribed material the term customer is used much more frequently compared to user (512 times, vs. 12 times).

Although some interviewees seems to employ customer and user as synonyms, "We have a large group of customers that is not a homogeneous group, to truly understand the essence of what they need to achieve, and for us to be able to find something that fits quite a few, not all, but many" [6:C]

Others show awareness of this problem "First, there are different types of customers, we start with that, one of the most important things is to actually understanding who the customer is, as the concept of customer is very very difficult, so we have even begun to talk about customers and end users, as two different" [12:D]

Consequently, a shift towards services seem to put the customer, and perhaps the user, more readily in mind in the developers of services. Since the users are the main focus within an HCI perspective this is an interesting correspondence between service and UCD.

\subsection{Service over Time}

An important aspect shared between HCI and service development is that the value of the result is created over time. In contrast to a product perspective where the product is finite and defined at the very moment of construction, both a HCI and service perspective presuppose a user who becomes acquainted with the system and becomes more skilled over time. Both HCI and service perspectives values long relations and the learning process which the users or customers provides. When it comes to services, this long relationship also involves a continuous development as in this quote: "One of the challenges for us is to find other service opportunities that enables us to have a more continuous contact with the customer, so we can have that ongoing relationship, and [remote] services are very good, very good area that makes sure we have a more continuous contact with those who actually use the services, first we get to know our customers better, they can tell you continuously what are the problems, it becomes a more natural contact with them because they understand, well they can actually help me with something" [12:D] 
It even seems like the service perspective, at least from our interviewees point of view, naturally includes a life-cycle awareness: "you need a life-cycle view, you can not only have development because then you miss the big maintenance an end of life part of service" [8:B]

This would imply that at least for these interviewees, a within the HCI field sought after perspective of longevity comes naturally when working with services and service development.

\section{Discussion}

This paper has elaborated on results from interviews with people working with service at four global technology-intensive companies. The interviews showed that the increased focus on service is an initiative from top management, but also that new ways of thinking is hard to implement. This is due to, on one hand, that the product oriented view reinforces a silos structure of the organization, while services to some degree need to transcend several departments, and on the other hand, service as a concept has so far been ill-defined and can connote different things. Note that both size of the company and the market probably is of importance for servitization and this analysis do not claim to inform the situation for smaller companies.

Furthermore, the large range of service types and the rapid technical development leads to the introduction of new types of services, e.g. software-supported services, and it also increase the confusion. What is referred to as service or product depends on your perspective, or viewpoint [19], often related to what view the company want to market.

One consequence of the concept confusion is that it makes service difficult to relate to during service development [20]. It is important that everybody involved in development has a similar idea of the service and it is likewise interpreted by all [21]. Rexfelt et al. found in an industrial context that a non-agreed upon definition about service turned it into a concept with no real meaning for the participants taking part in the studied service development project [22]. There were negative consequences for development of new service in this case.

Analytically we have scrutinized how service as a contemporary perspective is related to UCD and usability. We can see many similarities such as a focus on the client's needs and goals, as well as how the value of the result is created over time. However the focus on the client or customer can differ somewhat between service and UCD, since UCD as a systems development process is focusing on the actual user of a computer system. In contrast, service perspectives fluctuate between different roles with responsibility for certain processes within the recipient organization, as well as the actual user of a system or several systems. To complicate things even more, these systems might not originate from the delivering organization. Consequently, the service organization of a supplier company must then also have knowledge of the client organization and how they can be integrated in with the supplied products and services. This kind of value creation on a higher hierarchical level for the organization as a whole is lacking in definitions of usability [5], where the goal is met as long as the 
end-user is satisfied. Taking a service perspective on the other hand, thus makes one not only focus on the actual product, but also the value and enablement of the product for the client. A service perspective in the organization may impose more focus on the value of the reliability of the product than on the constitution of the product. Service thus is value-sensitive rather than product sensitive, interestingly such perspective have also been advocated within the UCD community [18].

The move towards an increased number of service solutions puts a focus on the experience of the receiver. In turn, this places new requirements on the delivering organization, which has to act in harmony and give the impression of acting as one entity towards the beneficiary. To make this possible, the people involved, their tools and policies, as well as their tasks needs to be understood and related to each other as a larger system. Development of solutions adapted to this reality, calls for a multi-level approach taking tasks, tools as well as organizational aspects into account.

In the interviews, we have noted an understanding of key concepts important for UCD, among people working with service. At the same time, there are economic incentives for upper management in these companies to invest in service. We argue that this is an opportunity to build on already established practices for user-centered design applied within these organizations for service development, a development currently done to a large extend by engineers. The access to professionals with UCD competence is limited today in these types of companies, and will be during a foreseeable future. Hence, a pre-understanding of these concepts will possibly facilitate introduction of a new way to approach service development building on experiences and learnings from the UCD tradition.

When shifting the focus from the product and hence the transaction, to service, there is also a shift to the relationships. Consequently, we see the opportunity for the usability community to take advantage of an increased attention on shared interests. Following this shift in perspective, we feel the hope for an increased perceived significance of what is considered foundations of UCD.

\section{Acknowledgments}

We would like to thank those we have been in contact with within these companies. We would also thank the anonymous reviewers for their input.

\section{$7 \quad$ References}

1. Oliva, R., Kallenberg, R.: Managing the transition from products to services. International Journal of Service Industry Management. 14, 2, 160-172 (2003)

2. Winter, J.K., Rönkkö, K., Rissanen, M.: Identifying organizational barriers- a case study of usability work when developing software in the automation industry. Journal of Systems and Software. 88, 54-73 (2014)

3. Bannon, L.: From human factors to human actors: The role of psychology and humancomputer interaction studies in system design. In: Greenbaum, J., Kyng, M. (eds.) Design 
at work: Cooperative design of computer systems. pp. 25-44. Lawrence Erlbaum Associates, New Jersey (1991)

4. Gould, J.D.: How to design usable systems. In: Helander, M., Landauer, T.K., Prabhu, P. (eds.) Handbook of Human-Computer Interaction. pp.757-789. Elsevier, North-Holland (1988)

5. Law, E.L-C, Lárusdóttir, M.K.: Whose Experience Do We Care About? Analysis of the Fitness of Scrum and Kanban to User Experience (UX). International Journal of HumanComputer Interaction. just-accepted (2015)

6. International Standard, ISO 9241-11 Guidance on Usability (1998)

7. International Standard, ISO/IEC 12207-2008 Systems and software engineering - Software life cycle processes (2008)

8. Bødker, S.: When Second Wave HCI meets Third Wave Challenges. In: NordiCHI 2006, Oslo, Norway (2006)

9. Shostack, G.L.: Breaking Free from Product Marketing. Journal of Marketing. 41, 2, 37-80 (1977)

10. Vargo, S.L., Lusch, R.F.: Evolving to a New Dominant Logic for Marketing. Journal of Marketing. 68, 1, 1-17 (2004)

11. Ostrom, A. L., Bitner, M. J., Brown S. T., Burkhard, K. A., Goul, M., Smith-Daniels, V., Demirkan, H., Rabinovich, E.: Moving forward and making a difference: Research priorities for the science of service. Journal of Service Research. 13, 1, 4-36 (2010)

12. Morelli, N.: Designing Product/Service Systems: A Methodological Exploration. Design Issues. 18, 3, 3-17 (2002)

13. Stickdorn, M., Schneider, J.: This is service design thinking: Basics, tools, cases. BIS Publishers, the Netherlands (2011)

14. Holmlid, S.: Participative, co-operative, emancipatory: From participatory design to service design. In: First Nordic Conference on Service Design and Service Innovation 1-14 (2009)

15. Wetter Edman, K.: The concept of value in design practice - an interview study. In: Second Nordic Conference on Service Design and Service Innovation 87-100 (2010)

16. Wetter Edman, K.: Design for Service: A framework for articulating designers' contribution as interpreter of users' experience. University of Gothenburg (2014)

17. Charmaz, K.: Constructing Grounded Theory: A Practical Guide Through Qualitative Analysis. SAGE Publications, London, UK (2006)

18. Friedman, B., Kahn, P., Borning, A.: Value sensitive design: Theory and methods. Technical report, 2-12, University of Washington (2002)

19. Norman, D. A.: Living with complexity. MIT Press, UK (2010)

20. Menor, L., Tatikonda, M., Sampson, S.: New service development: areas for exploitation and exploration. Journal of Operations Management. 20, 2, 135-157 (2002)

21. Clark, G., Johnston, R., Shulver, M.: Exploiting the service concept for service design and development. In: Fitzsimmons, J., Fitzsimmons, M. (eds.) New service design. Sage, Thousand Oaks, CA (2000)

22. Rexfelt, O., Almefelt, L., Zackrisson, D., Hallman, T., Malmqvist, J., Karlsson, M.: A proposal for a structured approach for cross-company teamwork: a case study of involving the customer in service innovation. Research in Engineering Design. 22, 153-171 (2011) 